J. Hazard. Mater. (2008), doi:10.1016/j.jhazmat.2008.04.086

(on line desde 29 de abril de 2008)

\title{
Resistance of Class C Fly Ash Belite Cement to Simulated Sodium Sulphate Radioactive Liquid Waste Attack
}

\author{
A. Guerrero ${ }^{a}$, S. Goñi ${ }^{*}$ and V.R. Allegro ${ }^{a}$ \\ ${ }^{a}$ Eduardo Torroja Institute for Construction Science (CSIC) \\ C/ Serrano Galvache, 4, 28033 Madrid, Spain \\ Tele.: $34913020440(284)$ \\ FAX: 34913020700 \\ E- mail: sgoni@ietcc.csic.es; aguerrero@ietcc.csic.es; allegro@ietcc.csic.es
}

The resistance of class $\mathrm{C}$ fly ash belite cement (FABC-2-W) to concentrated sodium sulphate salts associated with (LLW) and medium level wastes (MLW) is discussed. This study was carried out according to the Koch and Steinegger methodology by testing the flexural strength of mortars immersed in simulated radioactive liquid waste rich in sulphate (48 000 ppm) and demineralised water (used as a reference), at $20^{\circ} \mathrm{C}$ and $40^{\circ} \mathrm{C}$ over a period of 180 days. The reaction mechanisms of sulphate ion with the mortar was carried out through a microstructure study, which included the use of Scanning electron microscopy (SEM), porosity and pore-size distribution and X-ray diffraction (XRD). The results showed that the FABC mortar was stable against simulated sulphate radioactive liquid waste (SSRLW) attack at the two chosen temperatures. The enhancement of mechanical properties was a result of the formation of non-expansive ettringite inside the pores and an alkaline activation of the hydraulic activity of cement promoted by the ingress of sulphate. Accordingly, the microstructure was strongly refined.

Keywords: Fly-ash belite-cement; durability; sulphate waste; microstructure. 


\section{Introduction}

There are many important factors that negatively affect the stability of Portland cements against expansive reactions like the alkali-silica reaction (ASR); the sulphate attack, where destructive ettringite and/or gypsum is formed or can alter bentonite. Bentonite is typically used as a potential geological barrier for underground high level waste (HLW) repositories. Such problematic elements include the high $\mathrm{pH}$ of the pore solution together with the portlandite $\left(\mathrm{Ca}(\mathrm{OH})_{2}\right)$ content and the high heat of hydration of Portland cement.

It is well known that adding compounds with pozzolanic properties to Portland cement, such as fly ash (FA), blastfurnace slag (BFS), silica fume (SF) or metakaolin (MK), can reduce the aforementioned undesirable properties [122]. These improvements in cement quality can be attributed to the dense microstructure promoted by the pozzolanic reaction. This reaction considerably reduces the aggressive ingress of the surrounding environment by means of interconnected pore channels. In addition the dilution effect, the pozzolanic reaction decreases the alkalinity levels of the hydrated Portland cement pore solution, the $\mathrm{Ca}(\mathrm{OH})_{2}$ content and the heat liberated during hydration.

Radioactive liquid wastes (RLW) contain high levels of concentrated dissolved salts, such as sodium sulphate, due to the high volume of RLW that has to be reduced by means of an evaporation process. During evaporation, 
water is removed and the different salts are concentrated, giving rise to the "evaporator concentrates", which are referred to as simulated radioactive liquid wastes (SRLW) in this study.

Due to the advantages of pozzolanic additions, a pozzolanic Spanish cement (type IV), which is a mixture of Portland clinker (55\%), pozzolanic fly ash (ASTM class F) (40\%) and calcite filler (5\%) has been chosen to make a backfilling mortar. This type of mortar is used in Spain to ensure the immobilization of the radioactive cemented matrices inside concrete containers. Past durability investigations carried out in this laboratory revealed the good behaviour of this pozzolanic cement mortar in SRLW, which was very rich in sulphate [23-28]. It was found that the ingress of sulphate into the microstructure activated the pozzolanic reaction, which promoted a denser microstructure [28].

This work is part of an extensive investigation on the development of belite cements of low energy. These cements are being synthesised in this laboratory by using as secondary raw material different kinds of fly ash from coal combustion [29-34]. Apart from the environmental advantages attributed to the reduction in energy consumption, $\mathrm{CO}_{2}$ emissions and natural raw materials consumption, fly ash belite cements (FABC) have potential applications in the immobilization of SRLW [34]. 
First, these cements have a slow hydration rate, which gradually releases heat and prevents retraction; Second, the $\mathrm{pH}$ of the pore solution is lower than that of Portland cement. Finally, during its hydration, no $\mathrm{Ca}(\mathrm{OH})_{2}$ is produced.

In the present work, the resistance of class $\mathrm{C}$ fly ash belite cement (FABC-2-W) to highly concentrated sodium sulphate salts that accompanied the low (LLW) and medium (MLW) level wastes is discussed. This study was carried out, according to the Koch and Steinegger methodology [35], by testing the flexural strength of mortars immersed in both the simulated radioactive liquid waste that is rich in sulphate (48000 ppm) and demineralised water (used as a reference). These experiments were carried out at $20^{\circ} \mathrm{C}$ and $40^{\circ} \mathrm{C}$ during a period of 180 days. A microstructure study of the reaction mechanisms of both sulphate and sodium ions together with the mortar was accomplished with scanning electron microscopy (SEM), porosity and pore-size distribution and Xray diffraction $(X R D)$.

\section{Experimental}

The FABC-2-W was synthesised through the hydrothermal-calcination reaction using fly ash class $\mathrm{C}$, from coal combustion, as a secondary raw material. Details of the synthesis and fly ash can be consulted in reference 31 . The chemical compositions of the anhydrous cement and starting fly ash, as measured by UNE $80-215-88$ or EN 196-2, are listed in Table 1; the phase constitution (XRD) is shown in Fig. 1.The FA-2 is in accordance with the 
requirements of ASTM Class $C$ and the EN-UNE 450 specifications $\left(\mathrm{SiO}_{2}+\mathrm{Al}_{2} \mathrm{O}_{3}+\mathrm{Fe}_{2} \mathrm{O}_{3}\right.$ contents lower than $70 \%$, a high $\mathrm{CaO}$ content, and a $\mathrm{CaO} / \mathrm{SiO}_{2}$ molar ratio of 1 ). The mineralogical composition of the $\mathrm{FA}-2$ is given in Fig. 1(a). The crystalline compounds include free lime (CaO), anhydrite $\left(\mathrm{CaSO}_{4}\right)$, quartz $\left(\mathrm{SiO}_{2}\right)$, hematite $\left(\mathrm{Fe}_{2} \mathrm{O}_{3}\right)$, magnetite $\left(\mathrm{Fe}_{3} \mathrm{O}_{4}\right)$ and mullite $\left(\mathrm{A}_{3} \mathrm{~S}_{2}\right)$ $\left(\mathrm{Al}_{6} \mathrm{Si}_{2} \mathrm{O}_{13}\right)$. An amorphous halo appeared between the 15 and $352 \theta$ angular zone, which corresponds to the glassy component of fly ash. In the case of anhydrous FABC-2-W (Fig. 1(b)), broad reflections appeared in the 32-33 $2 \theta$ angular zone, which corresponds to the $\alpha^{\prime}-\mathrm{C}_{2} \mathrm{~S}\left(\mathrm{Ca}_{2} \mathrm{SiO}_{4}\right)$ belite variety with poor crystallinity; gehlenite $\left(C_{2} A S\right)\left(C_{2} A_{2} S_{i O}\right)$, traces of mayenite $\left(C_{12} A_{7}\right)$ $\left(\mathrm{Ca}_{12} \mathrm{Al}_{14} \mathrm{O}_{33}\right)$ and calcite $(\mathrm{Cc})\left(\mathrm{CaCO}_{3}\right)$ were also detected.

The FABC-2-W cement mortar was prepared with sand ( $\alpha$-quartz) with a cement ratio of 3 and a deionised water to cement ratio of 0.65 . For workability reasons, an organic additive (commercial name "Rheobuild-1000" Degussa Construction Chemicals, Barcelona, Spain) was introduced in a proportion of $2 \%$ (by weight of cement). After mixing, different portions were moulded into $1 \mathrm{~cm} \times 1 \mathrm{~cm} \times 6 \mathrm{~cm}$ prismatic specimens and compacted by vibration. After 2 days at $100 \%$ relative humidity (R.H.), samples were demoulded and cured by immersion in demineralised water at $40^{\circ} \mathrm{C}$ for 7 days. The volume of water was $100 \mathrm{ml}$ per six samples. After this curing period, groups of six samples were immersed and suspended in the SSRLW (concentration of sulphate $=48000$ ppm). These samples were stored in sealed plastic bottles at $20^{\circ} \mathrm{C}$ and $40^{\circ} \mathrm{C}$ for periods of $1,7,14,28,90$ and 180 days. The volume of SSRLW was $800 \mathrm{ml}$ per 
6 samples. Similar groups of six samples were stored at two temperatures in demineralised water (used as a reference).

X-ray diffraction patterns were recorded with a Philips PW-1730 diffractometer, which used a graphite monochromator and $\mathrm{Cu} \mathrm{K} \alpha 1$ radiation. Porosity and pore-size distribution were investigated by mercury intrusion porosimetry carried out with a Micromeritics Auto Pore IV 9500 v1.05. SEM analysis was performed using a JEOL JSM 5400 microscope (Ltd., Tokyo, Japan) equipped with an Oxford ISIS model EDX spectroscopy module (Oxford University, Oxford, UK). Sputtering was used to cover the samples with carbon.

The $\mathrm{pH}$ of the pore solutions was estimated by dissolving $1 \mathrm{~g}$ of powdered sample in $4 \mathrm{~mL}$ of demineralised water. The mixture was maintained for 1 day at ambient temperature, after which time the solid was filtered and the liquid was analysed. The $\mathrm{pH}$ was measured with a combined electrode for the $\mathrm{pH}$ range $0-14$

\section{Results and discussion}

Figure 2 shows the changes in flexural strength caused by the immersion of FABC-2-W cement mortars in demineralised water and in SSRLW solution at the two temperatures considered $\left(20^{\circ} \mathrm{C}\right.$ and $\left.40^{\circ} \mathrm{C}\right)$. Each value represents the average of six measurements, and the bars represent the standard deviation of 
the mean values. Time 0 in the figures correspond to samples cured for 7 days at $40^{\circ} \mathrm{C}$ in water before starting the potential attack.

When mortars are immersed in water at $20^{\circ} \mathrm{C}$, flexural strength values are quite similar and almost do not change throughout the experiment. At $40^{\circ} \mathrm{C}$, the flexural strength values slightly increase up to 90 days, and thereafter decrease considerably.

The mechanical strength of mortars immersed in the SSRLW solution increased with time according to a double logarithmic function. This effect was more marked at $40^{\circ} \mathrm{C}$, where the increase in strength (slope of the equation) was near two times higher respected to that of $20^{\circ} \mathrm{C}$. The decrease observed after 90 days of immersion was not as strong as that observed in water.

The Koch-Steinegger test [35] is the criterion to classify a material as resistant or durable in a specific aggressive medium. According to this test, the corrosion index (relative strength of aggressive -solution-stored (Fs') samples to water-stored ones (Fs)) must be higher than 0.7. As shown in Fig. 2, the corrosion index values increased with time according to a double logarithmic function with a slope about two times higher at $40^{\circ} \mathrm{C}$. This result suggests that the FABC-2-W can be classified as durable or resistant to the SSRLW attack, during the period of time and experimental conditions studied. 
The enhancement of mechanical behaviour is related to the microstructure changes. These changes can be produced by the diffusion of sodium and sulphate ions into the mortars and precipitation of new compounds, mainly of ettringite type $\left(3 \mathrm{CaO} \cdot \mathrm{Al}_{2} \mathrm{O}_{3} \cdot 3 \mathrm{CaSO}_{4} \cdot 32 \mathrm{H}_{2} \mathrm{O}\left(\mathrm{AF}_{\mathrm{t}}\right)\right)$, within pores as observed through XRD (Fig. 3) and SEM analyses (Fig. 4). This precipitation process decreased the porosity, causing a higher mechanical strength of the mortars. Another process, which could influence the mechanical behaviour of the belite mortars that were immersed in the SSRLW, would be an activation of the hydraulic activity of belite cement caused by the ingress of sodium and sulphate ions. This ingress increases the $\mathrm{pH}$ of the pore solution, as can be seen in Fig. 5. This increase may be a result of the ettringite formation reaction from the AFm phases, whose XRD peaks disappeared when the belite mortars were immersed in the SSRLW (compared Fig.3 (a)(b) with (c)(d)). The reaction mechanism for the formation of ettringite is hypothesised as follows:

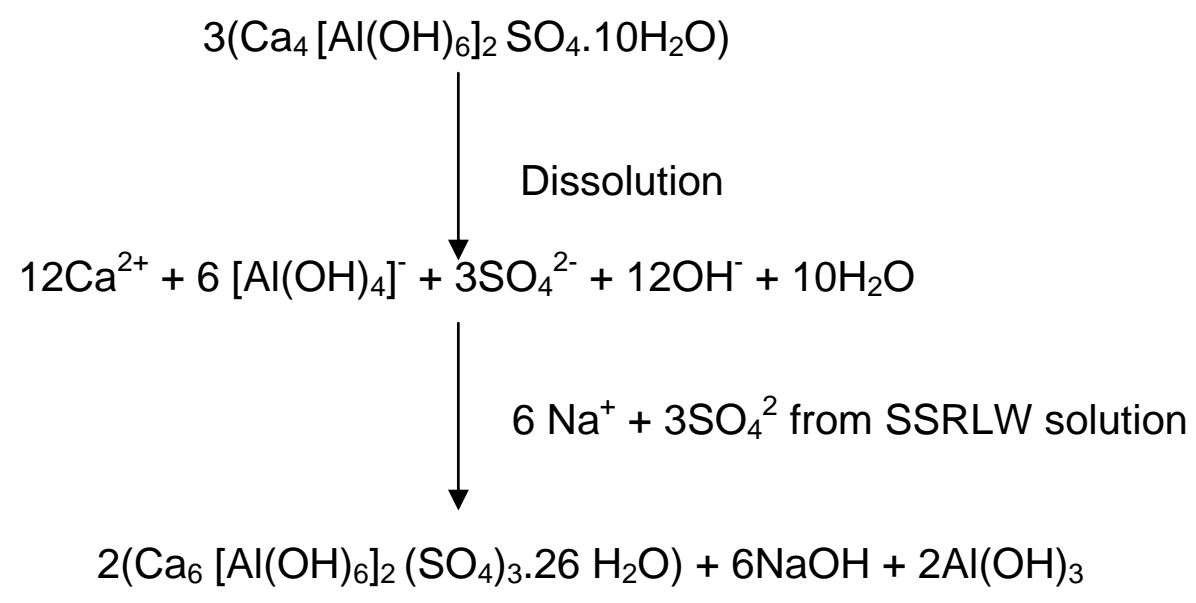

The increase of $\mathrm{pH}$ would activate the hydraulic activity of belite cement, which is in agreement with the lower intensity of the main XRD peak of the 
anhydrous $\alpha^{\prime} \mathrm{C}_{2} \mathrm{~S}$ (at 32 (20 angular zone)) in the mortars immersed in SSRLW solution (see Fig. 3 (c ) and (d)).

Similar results were found in $[1,2]$, and in the case of a pozzolaniccement mortar (employed in Spain to ensure the immobilisation of the radioactive cemented matrices inside concrete containers), the ingress of sodium and sulphate towards the porous microstructure activated the pozzolanic reaction $[25,28]$. Accordingly, the porosity was strongly refined and the mechanical properties were enhanced.

Both processes, the formation of ettringite within pores and the subsequent alkaline activation of belite cement, provoked a refinement of the porous microstructure as can be seen in Fig. 6 . In this case, the porosities of the belite mortars, after 180 days of immersion in the SSRLW solution, decreased and the pore-size distribution shifted to lower pore-diameter values with respect to those immersed in water for the same time. For samples immersed in water at $40^{\circ} \mathrm{C}$ resulted in an increase in amount of pore through a range of 0.1 to $1 \mu \mathrm{m}$ in diameter

This effect of temperature is in agreement what was observed in previous work [33], and similar mechanisms can be applied in this case. These mechanisms include the formation of katoite from low-density paste constituents (compare Fig. 3 (a) and (b)) and the polymerisation of the $\mathrm{C}-\mathrm{S}-\mathrm{H}$ gel, 
converging in the formation of larger capillary pores, which in turn causes a decreased flexural strength.

Figure 7 presents an important quantitative correlation between values for the mean pore diameter and flexural strength, which corroborates the modelling of the mechanism, involved during the immersion of the belite mortars in the SSRLW.

\section{Conclusions}

- According to the Koch-Steinegger test, the FABC-2-W cement mortar can be catalogued as resistant to the simulated sulphate radioactive liquid waste based on the concentration and experimental conditions studied.

- The ingress of sulphate and sodium into the microstructure of the FABC-2-W cement mortar caused the formation of non-expansive ettringite inside the pores.

- Due to the lack of portlandite, ettringite is formed from the dissolution of monosulfo phases (AFm type), which significantly increases the $\mathrm{pH}$ of the simulated pore solution.

- It is postulated that this increase of $\mathrm{pH}$ activated the hydraulic activity of the belite cement.

- As a consequence of both the ettringite formation and the alkaline activation of the cement, the porous microstructure became denser, and the flexural strength increased.

- This effect was faster at $40^{\circ} \mathrm{C}$. 
- Important quantitative correlations between microstructural parameters such as the mean pore diameter and macrostructural mechanical strength were found.

\section{Acknowledgements}

Funding for the present research was provided by the Minister of Science and Technology under Project n MAT 2002-04023-CO3. The authors wish to thank the Thermal Station of Cercs (Catalonia) for the fly ash supplied.

\section{References}

[1] Al-Dulaijan SU, Macphee DE, Maslehuddin M, et al, Performance of plain and blended cements exposed to high sulphate concentrations, Adv. Cem. Res. 19 (4) (2007) 167-175.

[2] Al-Zahrani MM, Performance of plain and blended cements exposed to varying concentrations of sodium sulphate, Adv. Cem. Res. 19 (4) (2007)177-184.

[3] Céline Cau Dit Coumes, Simone Courtois, Didier Nectoux, Stéphanie Leclercq, Xavier Bourbon, Formulating a low-alkalinity, high-resistance and low-heat concrete for radioactive waste repositories, Cem. Concr. Res. 36 (2006) 2152-2163. 
[4] M. Codina, C. Cau-dit-Coumes, P. Le Bescop, J. Verdier, J.P. Ollivier, Design and characterization of low-heat and low-alkalinity cements, Cem. Concr. Res. 38 (2008) 437-448.

[5] MP. Lorenzo. The effect of two kinds of Spanish fly ashes on the microstructure and durability of the hydrated Portland cement paste. Ph.D. thesis, University Complutense Madrid, Spain, 1993.

[6] S. Goñi, MP. Lorenzo J.L. Sagrera, Durability of hydrated Portland cement with copper slag addition in $\mathrm{NaCl}+\mathrm{Na} 2 \mathrm{SO} 4$ medium, Cem. Concr. Res. 24(8) (1994) 1403-1412.

[7] P.K. Mehta. Concrete, structure, properties and materials. New Jersey: Prentice-Hall, 1986, Hall WS, editor

[8] H. Uchikawa, Effect of blending components on hydration and structures formation, in: Proceedings of the 8th International Congress on the Chemistry of Cement (ICCC), Paris, 1986, 1, pp. 249-280.

[9] MP. Lorenzo, S. Goñi, MS. Hernandez, A. Guerrero, Effect of fly ashes with high total alkali content on the alkalinity of the pore solution of hydrated Portland cement paste, J. Am. Ceram. Soc. 79(2) (1996) 470474.

[10] S. Goñi, MP. Lorenzo, A. Guerrero, MS. Hernandez, Calcium hydroxide saturation factors in the pore solution of hydrated Portland cement fly ash pastes, J. Am. Ceram. Soc. 79(4) (1996) 1041-1046.

[11] MP. Lorenzo, S. Goñi, JL. Sagrera, Chemical changes in the poresolution of cement pastes with slag addition of copper, in: Blended 
Cements in Construction. London, UK: Elsevier Applied Science, RN. Swamy editor, 1991. pp. 125-137.

[12] I. Canham, CL. Page, PJ. Nixon, Aspects of the pore solution chemistry of blended cements related to the control of alkali silica reaction, Cem. Concr. Res. 17 (1987) 839-844.

[13] ALA. Fraay, JM. Bijen, YH. Haan, The reaction of fly ash in concrete: a critical examination, Cem. Concr. Res. 19 (1989) 235-246.

[14] ALA. Fraay, JM. Bijen, Cement-stabilized fly ash base courses, Cem. Concr. Comp. 12 (1990) 279-291.

[15] S. Diamond, Effects of two Danish fly ashes on alkali contents of pore solutions of cement-fly ash pastes, Cem. Concr. Res. 11 (1981) 383-392.

[16] FP. Glasser, J. Marr, The effect of mineral additives on the composition of cement pore fluids, Br. Ceram. Soc. Proc. 35 (1984) 419.

[17] PJ. Nixon, CL. Page, R. Bollinghaus, I. Canham, The effect of a Pfa with a high total alkali content on pore solution composition and alkali silica reaction, Mag. Concr. Res. 38 (134) (1986) 51-54.

[18] K. Torii, M. Kawamura, Effects of fly ash and silica fume on the resistance of mortar to sulfuric acid and sulfate attack, Cem. Concr. Res. 24 (2) (1994) 361-370.

[19] KW. Nasser, S. Ghosh, Durability properties of high strength concrete containing silica fume and lignite fly ash, ACl SP-145 (Durability of Concrete) (1994) 191-214.

[20] K. Torii, K. Taniguchi, M. Kawamura, Sulfate resistance of high fly ash content concrete, Cem. Concr. Res. 25(4) (1995) 759-768. 
[21] D. Krizan, B. Zivanovic, Resistance of fly-ash blended cement mortars to sulphate attack, in: Proceedings of the 10th International Congress on the Chemistry of Cement (ICCC), (1997) 4:4iv020.

[22] A. Erdal Osmanlioglu, Immobilization of radioactive waste by cementation with purified kaolin clay, Waste Management 22 (2002) 481-483.

[23] MaS. Hernandez, A. Guerrero, S. Goñi and MaP Lorenzo, Effect of the temperature on the leaching performance of the cement-based immobilization systems. Sulfate and chloride behaviour, Cem. Concr. Res., 26 (4) (1997) 515-524.

[24] A. Guerrero, Mas. Hernandez and S. Goñi, Durability of cement-based materials in simulated radioactive liquid waste: Effects of phosphate, sulphate and chloride ions, J. Mater. Res. 13 (8) (1998) 2151-2160.

[25] A. Guerrero, Mas. Hernandez and S. Goñi, The role of the fly ash pozzolanic activity in simulated sulphate radioactive liquid waste, Waste Manage, 20 (2000) 51-58.

[26] A. Guerrero, S. Goñi and Mas. Hernandez, Thermodynamic solubility constant of $\mathrm{Ca}(\mathrm{OH})_{2}$ in simulated radioactive sulfate liquid waste, J. Amer. Ceram. Soc., 83 [4] (2000) 882-888.

[27] A. Guerrero, Mas. Hernandez and S. Goñi, Effect of simulated radioactive liquid waste on the microstructure of cementitious materials: Portlandite orientation and saturation factors in the pore solution, $\mathrm{J}$. Amer. Ceram. Soc. 83 (11) (2000) 2803-2808. 
[28] Mari Paz Lorenzo, Sara Goñi, and Ana Guerrero, Activation of pozzolanic reaction of hydrated Portland cement fly ash Pastes in sulfate solution, J. Am. Ceram. Soc., 85 [12] 3071-75 (2002).

[29] A. Guerrero, S. Goñi, I. Campillo, A. Morague, Belite cement clinker from coal fly ash of high Ca content. Optimization of synthesis parameters, Environ. Sci. Technol. 38 (12) (2004), 3209-3213.

[30] S. Goñi, Elizalde, A. Guerrero, Bustos, A. Moragues, Terradas, MF. Tallafigo, Vidal, I. Campillo, Santos, J. Sánchez, Dolado and A. Porro, Fernández, "New belite cement clinkers from fly ash of coal combustion of high Ca content". Spanish Patent No ES 2223275 A1, published 16, February, 2005.

[31] J.S.Dolado, I. Campillo, E. Erkizia, J.A. Ibáñez, , A. Porro, A. Guerrero and S. Goñi, Effect of nanosilica additions on the Belite cement pastes held in sulphate solutions, J. Am. Ceram. Soc. 90 [12] (2007) 3973-3976.

[32] Sara Goñi and Ana Guerrero, SEM/EDX characterization of the hydration products of belite cements from coal fly ash class C, J. Am. Ceram. Soc. 90 [12] (2007) 3915-3922.

[33] Sara Goñi and Ana Guerrero, Modifications of the C-S-H gel by hydration at $40^{\circ} \mathrm{C}$ of two types of fly ash belite cements, J. Am. Ceram. Soc. 91 [1] (2008) 209-214.

[34] S. Goñi, and A. Guerrero, Efficiency of fly ash belite cement and zeolite matrices for immobilizing cesium, J. Hazard. Mater, B137 (2006) 160817 
[35] A. Koch und $\mathrm{H}$. Steinegger, A rapid method for testing the resistance of cements to sulphate attack, Zement-Kalk-Gips, 7 (1960) 317-324. 


\section{List of Captions}

Figure 1. X-ray diffraction patterns of the starting fly ash (FA-2) and anhydrous cement (FABC-2-W).

Figure 2. Flexural strength and corrosion index (Rf'/Rf) of mortar samples versus time, $\mathrm{Rf}^{\prime}=$ strength after immersion in the SSRLW; $\mathrm{Rf}=$ strength after immersion in water.

Figure 3. XRD patterns of mortar samples after 180 days of immersion in de-ionized water and simulated sulphated radioactive liquid waste (SSRLW) at the temperatures of $20^{\circ} \mathrm{C}$ and $40^{\circ} \mathrm{C}$.

Figure 4. SEM images of ettringite needles growing inside the pores of mortar samples after 180 days of immersion in simulated sulphated radioactive liquid waste (SSRLW).

Figure 5. Changes of the $\mathrm{pH}$ of the simulated pore solution of mortars after 180 days of immersion in de-ionized water and simulated sulfate radioactive liquid waste $(S S R L W)$ at the temperatures of $20^{\circ} \mathrm{C}$ and $40^{\circ} \mathrm{C}$.

Figure 6. Pore-size distribution curves of mortars samples after 180 days of immersion in de-ionized water and simulated sulfate radioactive liquid waste (SSRLW) at the temperatures of $20^{\circ} \mathrm{C}$ and $40^{\circ} \mathrm{C}$.

Figure 7. Quantitative correlation between the flexural mechanical strength and mean pore diameter. 


\section{Tables}

Table 1. Chemical Composition of the Starting Fly Ash (FA-2) and Belite cement (FABC-2-W) (\% by weight).

\begin{tabular}{|c|c|c|c|c|c|c|c|c|c|c|c|}
\hline & LOI $^{*}$ & $\mathrm{CaO}$ & $\begin{array}{l}\mathrm{SiO}_{2} \\
\text { (total) }\end{array}$ & $\mathrm{Fe}_{2} \mathrm{O}_{3}$ & $\mathrm{Al}_{2} \mathrm{O}_{3}$ & $\mathrm{MgO}$ & $\mathrm{SO}_{3}$ & $\mathrm{Na}_{2} \mathrm{O}$ & $\mathrm{K}_{2} \mathrm{O}$ & $\begin{array}{l}\mathrm{SiO}_{2} \\
\text { (reactive) }\end{array}$ & $\begin{array}{l}\text { BET } \\
\left(\mathrm{m}^{2} / \mathrm{gr}\right)\end{array}$ \\
\hline$F A-2$ & 4.0 & 32.0 & 32.8 & 4.2 & 19.3 & 2.2 & 2.8 & 0.44 & 1.6 & 25.2 & 3 \\
\hline$F A B C-2 W$ & 1.4 & 48.3 & 28.7 & 2.3 & 15.2 & 1.4 & 1.7 & 0.25 & 0.5 & 28.6 & 6.4 \\
\hline
\end{tabular}

${ }^{*} \mathrm{LOI}=$ loss on ignition; *Silica reactive according to Spanish standard UNE-80-224 


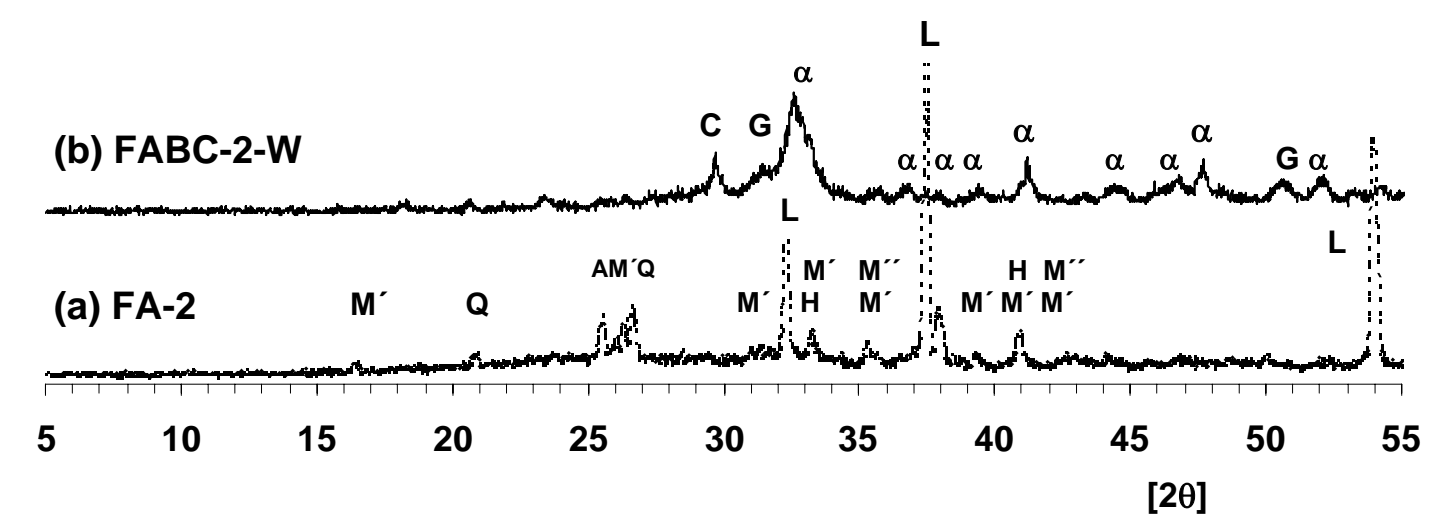

C calcite; G gehlenite; A anhydrite; Q quartz; M mayenite; M'mullite; M" magnetite; L lime; $H$ hematite ; $\alpha \alpha^{\prime}{ }_{L}-C_{2} S$

Figure 1. X-ray diffraction patterns of starting FA-2 and anhydrous FABC-2-W cement
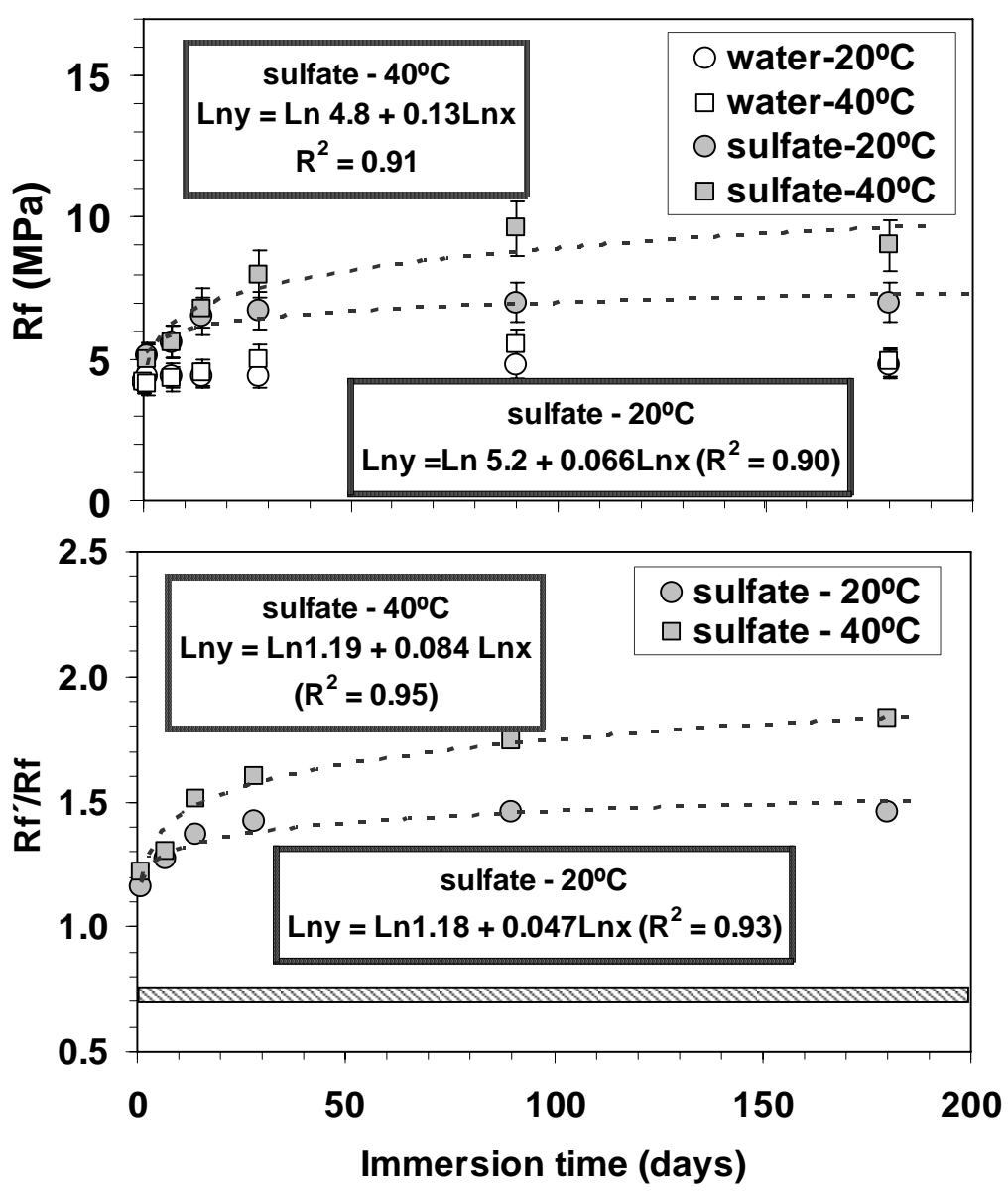

Fig. 2. Flexural strength and corrosion index (Rf'/Rf) of mortar samples versus time, $R f^{\prime}=$ strength after immersion in the SSRLW; Rf = strength after immersion in water. 


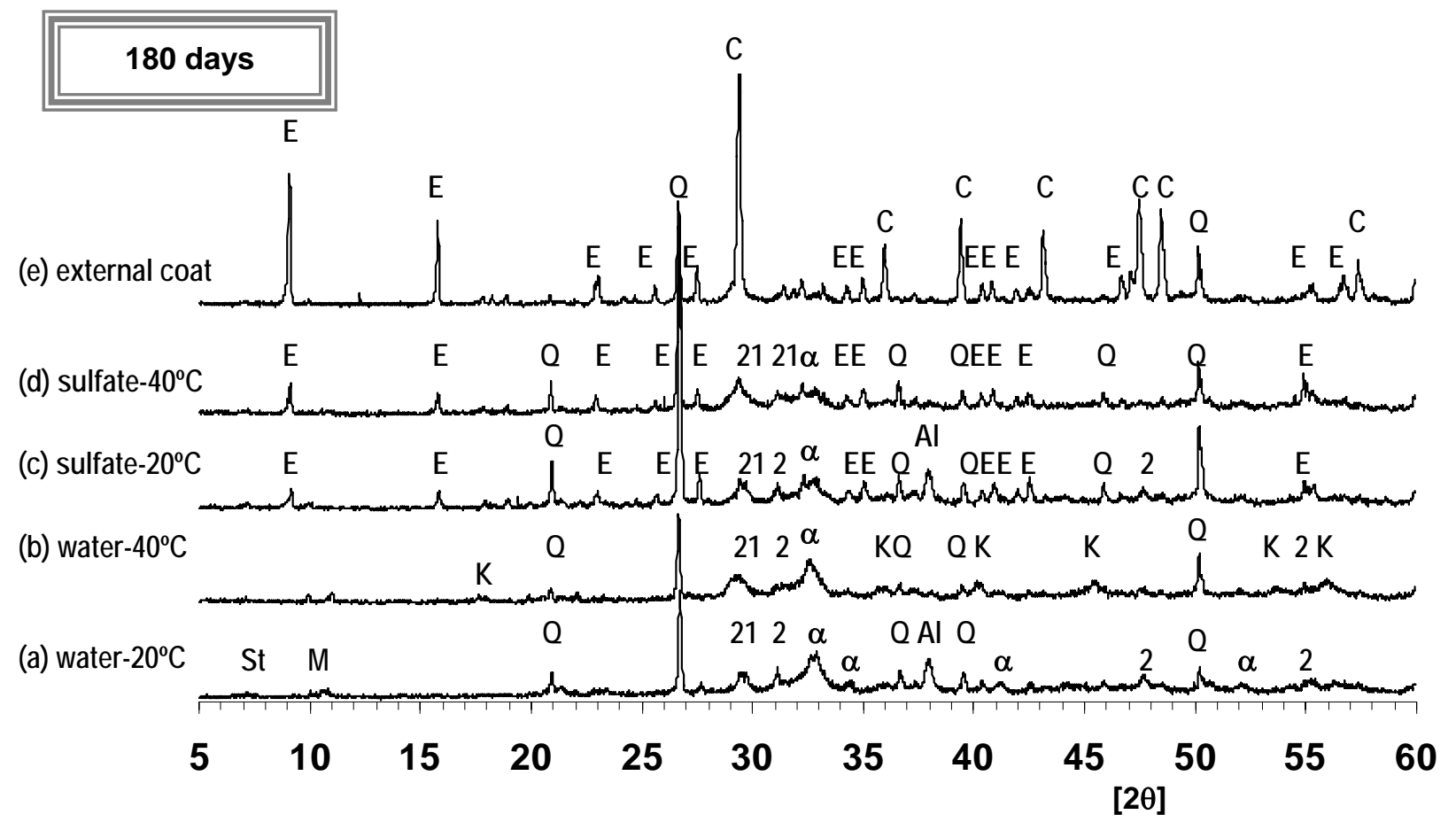

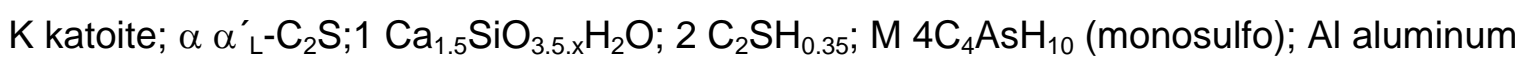
from sample holder; $\mathrm{E}$ ettringite; $\mathrm{C}$ calcite; St stranlingite.

Figure 3. XRD patterns of mortar samples after 180 days of immersion in de-ionized water and simulated sulphated radioactive liquid waste (SSRLW). Influence of temperature.

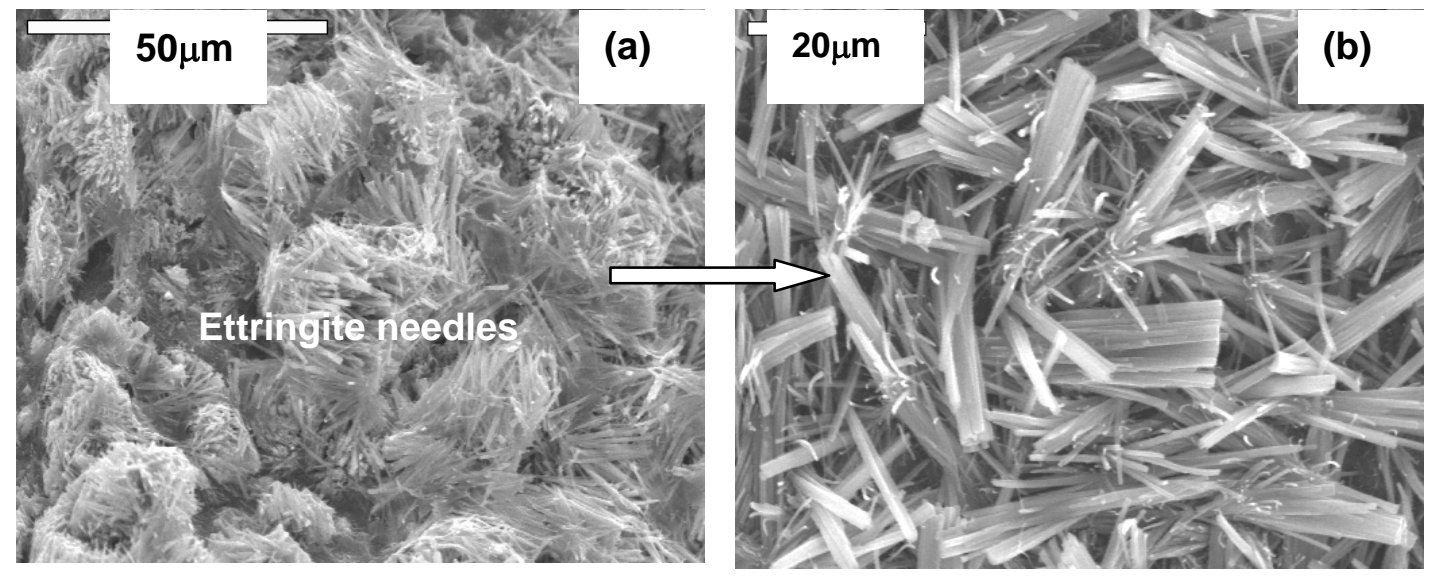

Figure 4. SEM images of ettringite needles growing inside the pores of mortar samples after 180 days of immersion in simulated sulphated radioactive liquid waste (SSRLW). 


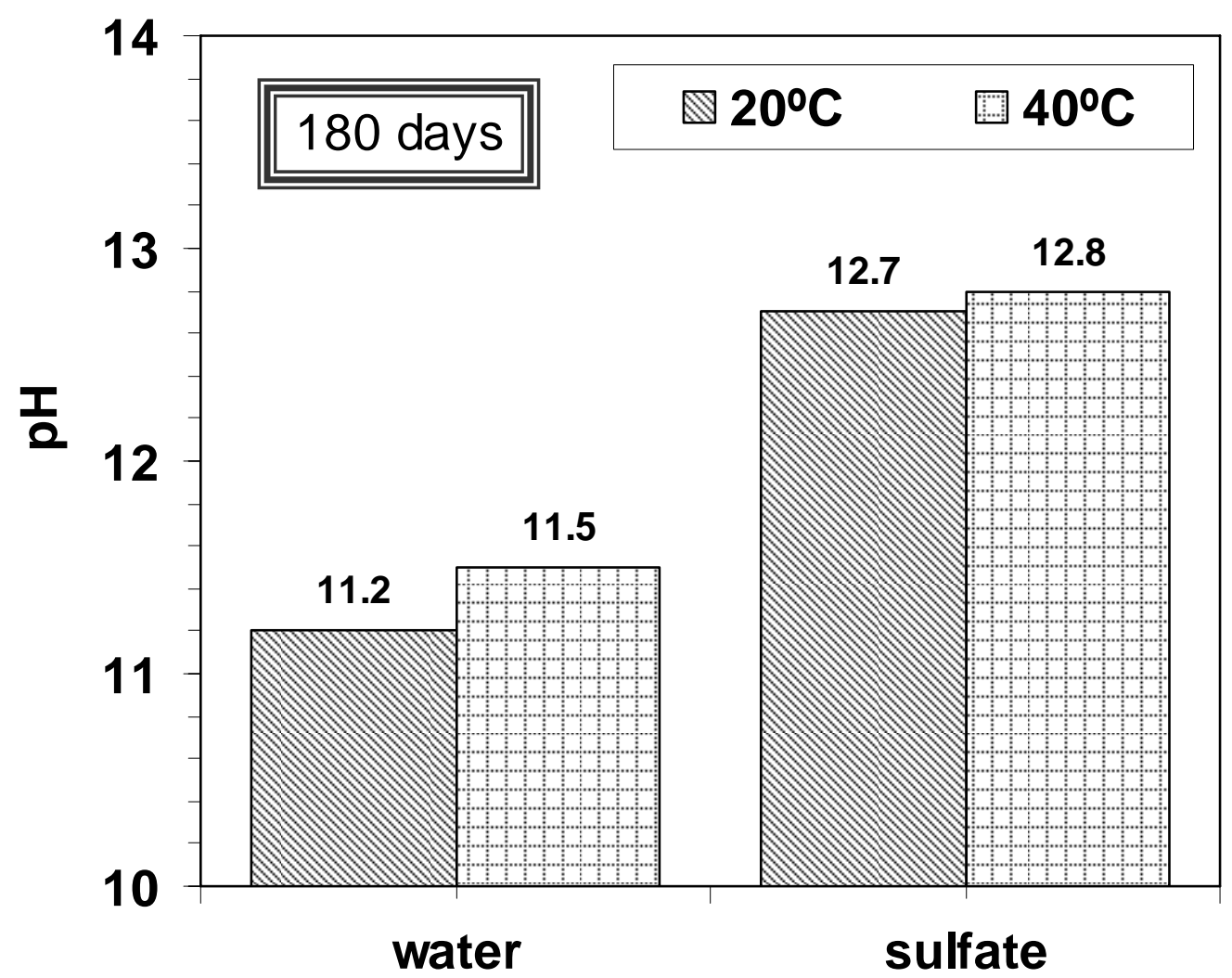

Figure 5. Changes of the $\mathrm{pH}$ of the simulated pore solution of mortars after 180 days of immersion in deionized water and simulated sulphate radioactive liquid waste (SSRLW) at the temperatures of $20^{\circ} \mathrm{C}$ and $40^{\circ} \mathrm{C}$. 

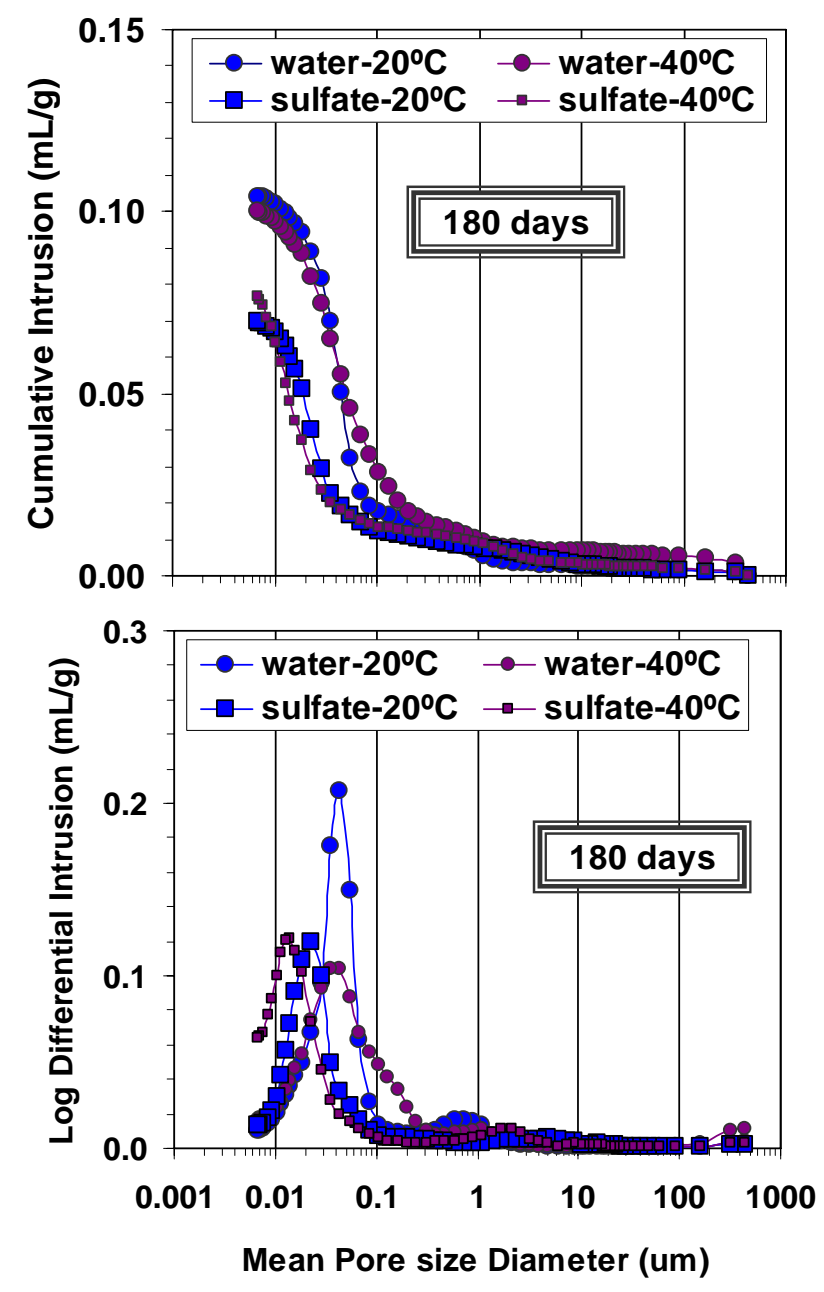

Figure 6. Pore-size distribution curves of mortars samples after 180 days of immersion in de-ionized water and simulated sulphate radioactive liquid waste (SSRLW) at the temperatures of $20^{\circ} \mathrm{C}$ and $40^{\circ} \mathrm{C}$. 


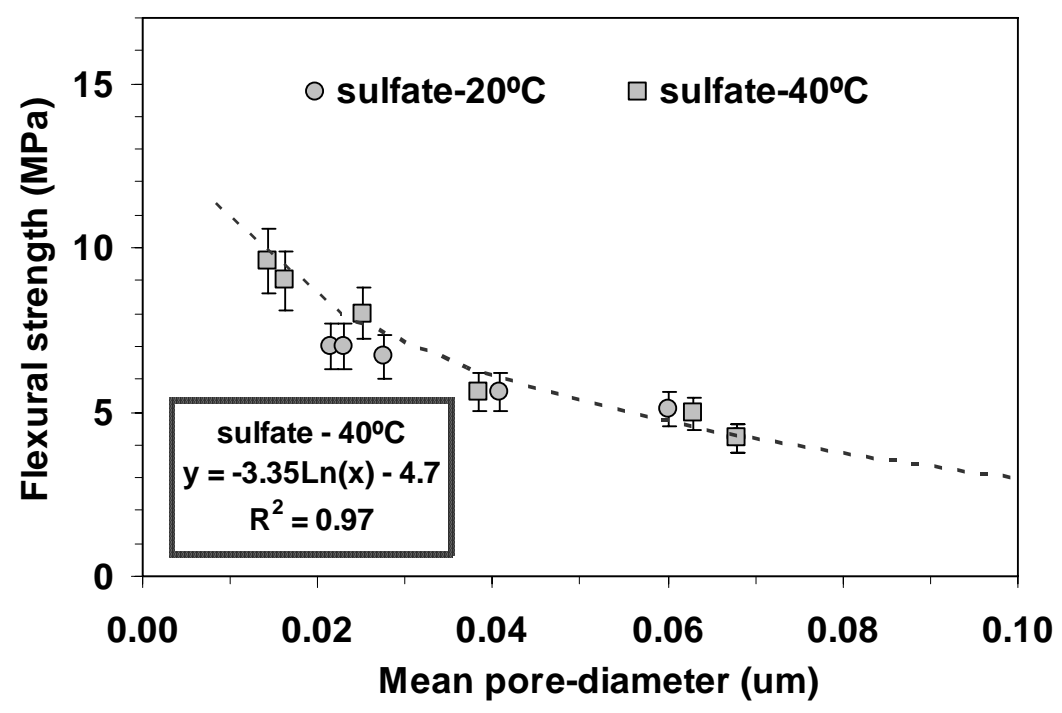

Figure 7. Quantitative correlation between the flexural mechanical strength and mean pore diameter. 